\title{
Management of Vertebral Malignant Tumors: Clinical and Radiographic Study
}

Tarek Aly*

Department of Orthopedic Surgery, Egypt

\begin{abstract}
26 patients underwent decompression-stabilization procedures for their malignant spinal lesions. Fifteen were females and 11 males. Their average age was 60.6 years (range 18-73 years). These patients were classified according to extent of involvement of the spine. One column was involved in $1 / 26(3.8 \%)$ case, two in $11 / 26$ cases (42.3\%) and three in $14 / 26$ cases $(53.8 \%)$. A posterior approach alone was done in $8 / 26(30.8 \%)$ patients while a combined anterior and posterior approaches were done in 18/26 (69.2\%) cases. A variety of posterior stabilization procedures were used. Out of 24 patients who were able to attend the follow-up $16(66.7 \%)$ were able to walk, five $(20.8 \%)$ were paraparetic, and 3 patients $(12.5 \%)$ were paraplegic. Patients with combined approach showed higher percentage of neurologic improvement $(62 \%)$ while patients with posterior approach showed only $35 \%$ improvement in their neurologic status. Accordingly results obtained from direct anterior approaches using corpectomy and anterior reconstruction of the anterior and middle columns have produced the best results in terms of neurological improvement. Almost all of our patients had 2 or 3 columns involvement but the results did not support the three columns theory where we could not correlate any significant results, regarding pre- or post-operative radiographic measurements (mechanical instability) and pre- or post-operative neurologic findings (neurologic instability), with the number of involved columns.
\end{abstract}

Keywords: Vertebral malignant tumors; Neurological diagnosis; Magnetic resonance

\section{Introduction}

With recent advances in oncology, an increasing number of patients with malignant lesions are surviving longer. During the past decade improvements in neurological diagnosis using magnetic resonance (MR) imaging, together with the development of instrumentation, have considerably expanded the role of surgery in the treatment of neoplasm of the spine [1]. Currently, both external irradiation and surgical decompression are considered standard treatment modalities. Surgical approaches have ranged from limited posterolateral decompression to more aggressive anterior approaches for vertebral body resection [2-5]. Although a single approach may suffice in most patients, radiographic studies frequently demonstrate three-column involvement or marked instability of the spine. In such patients a purely posterior or anterior approach does not provide sufficient access for tumor resection or correction of the instability. Thus, combined anterior-posterior approaches may be required [2]. Therefore, we have analyzed our series with malignant lesion of the lumbar and thoracic spine treated surgically to specify the effect of column involvement on the results.

\section{Material and Methods}

Twenty-six patients underwent decompression-stabilization procedures for their malignant spinal lesions. Fifteen were females and 11 were males. Their average age was 60.6 years (range $18-73$ years). All patients' specimens were subjected to histopathological examination. The primary tumors that caused the metastatic epidural compression in these patients are listed in Table 1.

\section{Indication for surgery}

The goals of treatment were to improve or preserve neurological function, reduce pain and allow early ambulation. The indications for surgery are rapid progressive cord compression, instability, and pain. All patients had a definite neural deficit. Muscle strength was assessed on a scale from 0 to 5 . Patients were divided into 3 clinical groups according to their muscle strength and motor function [6]. Paraplegia denoted no antigravity muscle function (0-1); Paresis denoted muscle strength of 2-3; and weakness, 4.3 patients (11.5\%) were paraplegic before surgery, $17(65.4 \%)$ were paretic (non-ambulatory), and 6

\begin{tabular}{|c|c|c|}
\hline Diagnosis & Number of patients & Percentage \\
\hline Breast & 9 & 34.6 \\
\hline Lung & 5 & 19.2 \\
\hline Hypernephroma & 4 & 15.4 \\
\hline Myeloma & 4 & 15.4 \\
\hline Hepatocellular carcinoma & 2 & 7.7 \\
\hline Prostate carcinoma & 1 & 3.8 \\
\hline Sarcoma and lymphoma & 1 & 3.8 \\
\hline
\end{tabular}

Table 1: Pathology of the tumors.

(23.1\%) were able to walk but suffered a definite neural dysfunction (Tables 2-4). Twelve patients (46.2\%) were continent, $11(42.3 \%)$ had bowel and bladder dysfunction, and 3 (11.5\%) patients were incontinent. Persistent pain was present in 22 patients (84.6\%). Both the cord and the cauda equina were compressed by a metastatic tumor and were considered as epidural spinal cord compression, as Livingston and Perrin [7] reported no difference in outcome. Instability was one of the major indications for surgery. Although the criteria for spinal instability for trauma have been well established by Denis [8] these may not always be relevant to patients with spinal tumors. Siegal and Siegal [9] proposed several criteria for spinal instability in patients with tumors which are outlined in Table 2. Patients were classified according to the involvement of the 3 columns of the spine. One column was involved in only one case (3.8\%), two columns were involved in 11 cases $(42.3 \%)$ and three columns were involved in 14 cases (53.8\%). The Kyphotic angles were measured according to the Cobb's method. In 14 patients (53.8\%) the level of compression was in the thoracolumbar spine (T10 to L1) and in 12

*Corresponding author: Tarek Aly, Department of Orthopedic Surgery, 48th, Sarwat street, Tanta 31111, Egypt, Tel: 2040 3317928; E-mail: elphara3on@hotmail.com

Received July 29, 2014; Accepted November 17, 2014; Published November 19,2014

Citation: Aly T (2014) Management of Vertebral Malignant Tumors: Clinical and Radiographic Study. J Spine 3: 190. doi:10.4172/2165-7939.1000190

Copyright: (c) 2014 Aly T. This is an open-access article distributed under the terms of the Creative Commons Attribution License, which permits unrestricted use, distribution, and reproduction in any medium, provided the original author and source are credited. 
1 Anterior \& middle column involvement or $>50 \%$ collapse of vertebral body height.

2 Middle \& posterior column involvement or shearing deformity

3 Three- column involvement

4 Involvement of the same column in two or more adjacent vertebrae latrogenic instability:

5 -Laminectomy performed to treat anterior \&/or middle column disease. -Resection of $>50 \%$ of cut surface of the vertebral body.

Table 2: Criteria indicating spinal instability in metastatic tumors [9].

\begin{tabular}{|l|c|c|}
\hline Methods & Number & Percentage \\
\hline Isola posterior spinal system & 7 & 26.9 \\
\hline Cotrel-Debousset system & 7 & 26.9 \\
\hline Harrington instrumentation & 2 & 7.7 \\
\hline Plates and pedicular screws & 3 & 11.5 \\
\hline Luque rods with sublaminar wiring & 1 & 3.8 \\
\hline TSRH spinal system & 1 & 3.8 \\
\hline No internal fixation & 5 & 19.2 \\
\hline
\end{tabular}

Table 3: Methods of internal fixation.

\begin{tabular}{|l|c|c|c|c|}
\hline Neurology & \multicolumn{2}{|c|}{ Preoperative } & \multicolumn{2}{c|}{ Postoperative } \\
\hline Walking ability & No. & Percentage & No. & Percentage \\
\hline Able to walk & $6 / 26$ & 23.1 & $16 / 24$ & 66.7 \\
\hline Paraparetic & $17 / 26$ & 65.4 & $5 / 24$ & 20.8 \\
\hline Paraplegic & $3 / 26$ & 11.5 & $3 / 24$ & 12.5 \\
\hline Bowel \& Bladder & & & & \\
\hline Continent & $12 / 26$ & 46.2 & $17 / 24$ & 70.8 \\
\hline Dysfunction & $11 / 26$ & 42.3 & $6 / 24$ & 25 \\
\hline Incontinent & $3 / 26$ & 11.5 & $1 / 24$ & 4.2 \\
\hline Pain & & & & \\
\hline Persistent & $22 / 26$ & 84.6 & $6 / 24$ & 25 \\
\hline
\end{tabular}

Table 4: Neurological recovery in all patients.

(46.2\%) patients in the lumbar spine (L2-L5). The planning of the surgical approach was based on standard radiographs of the spine followed by a computerized axial tomography and magnetic resonance scanning. A posterior spinal decompression was used in 8/26 (30.77\%) patients where the pathological change was posterior to the spinal cord. A combined anterior-posterior approach was performed in $18 / 26(69.33 \%)$ where an anterior spinal decompression was used for tumors affecting the anterior column of the spine and the anterior

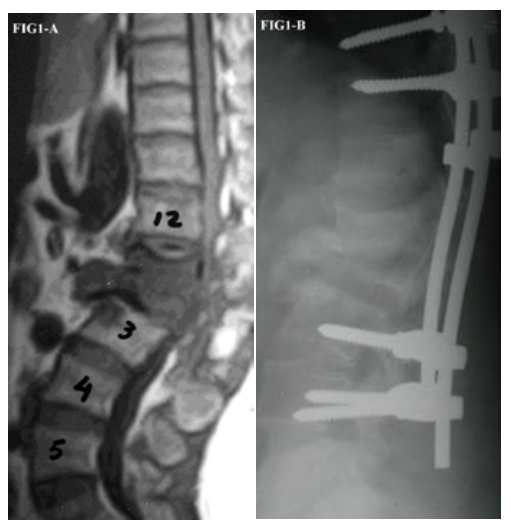

Figure 1: (A) MR image showing a collapsed vertebral body in a 48-yearold woman with breast cancer metastasis in L1-2. The patient had intensive radiating pain to the right groin. (B) Plain $\mathrm{x}$-ray film 1 week after surgery shows transpedicular fixation between T9-10 and L3-4.
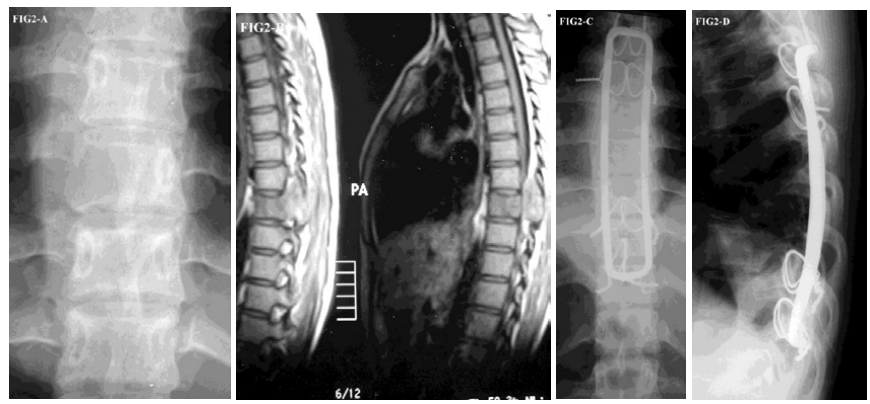

Figure 2: A) MR image and plain x-ray film revealing a case of three column involvement exhibited in cervical cancer metastasis to T-8 in a 52-year-old woman. (B): Tumor resection and stabilization with rectangle and sublaminar wiring were performed in two stages.
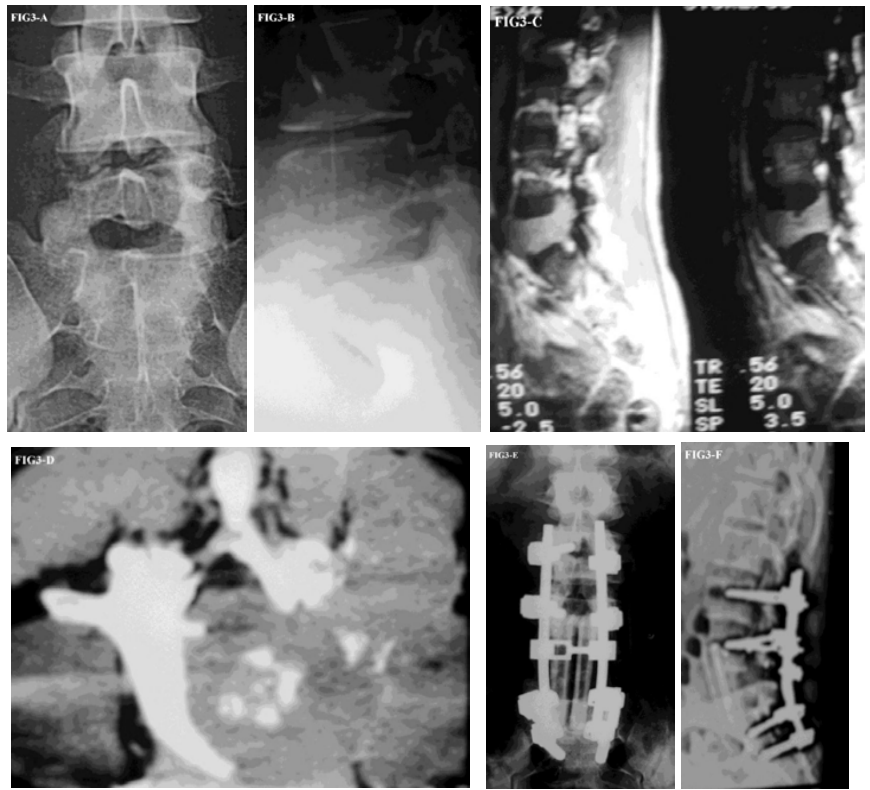

Figure 3: (A) Antero-posterior and lateral radiographs of renal cance metastasis to L5. (B) MR image showing destruction of the L5 vertebral body and the tumor growed into the epidural space. (C) Antero-posterior and lateral radiographs after combined antero-posterior decompression and fixation using a pedicle-fixating device with placement of a fibular autograft anteriorly.

part of the spinal canal or diffusely spread around it (Figures 1-3). The defect created by the removal of the tumor was filled by bone cement in $10 / 26$ cases $(38.5 \%)$, bone autograft taken from the iliac crest in $3 / 26(11.5 \%)$ (We use 3 pieces of corticocancellous iliac bone auto graft to be distributed in the removed vertebral area.), and free fibular graft in one (3.8\%), and bone allograft (frozen femoral head) in 4/26 cases $(15.4 \%)$. No grafting was performed in $8 / 26$ cases $(30.77 \%)$ after posterior spinal decompression. A variety of stabilization procedures were used, including Isola posterior spinal system, Cotrel-Debousset system, Harrington instrumentation, Plates and pedicular screws, Luque rods with sublaminar wiring and TSRH spinal system (Table 3).

\section{Postoperative care and follow-up}

All patients were fitted with a polypropylene thoracolumbosacral orthosis. Orthosis were worn for 3 months and the decision to wean was made on an individual basis. The average follow-up period was 23 months (range 13-38 months). All patients had postoperative radiation therapy except those irradiated before surgery $(n=7)$. 
A combination of Frankel grading [10] and the severity of pain assessed the clinical outcome. The severity of pain was classified as non-or negligible, mild (occasionally necessitating non-narcotic pain medication), moderate (often-necessitating pain medication, including narcotics), or severe (necessitating daily pain medication, including narcotics). Final evaluation was graded as excellent, good or bad. Excellent: Frankel grade E without pain Good: Frankel grade E with pain or Frankel grade D with or without pain. Bad: Frankel grade A, B, or $\mathrm{C}$ with or without pain. Statistical analysis was performed using the one way ANOVA test.

\section{Results}

Two patients died in the first 2 weeks after anterior spinal decompression. One of them was paraparetic and the other was able to walk before the surgical procedure. Lung carcinoma was the primary in these two patients. The outcome of only 24 cases could be assessed. No significant statistical relationship was found between patient's age and involved level $(\mathrm{P}=0.6462)$. The ability to walk, sphincter control and the effect on pain are outlined in Table 4.

Excluding those 2 patients who died 16 (66.7\%) were able to walk, $5(20.8 \%)$ were still paraparetic, and $3(12.5 \%)$ were paraplegic. One for the paraplegic patients made a good neurological recovery after anterior decompression and was able to walk and another patient deteriorated after decompression to paraplegia. After decompression 17/24 patients (70.8\%) regained normal sphincter control, and only one patient $(4.2 \%)$ was still incontinent. Correlation between pre- and post-operative Frankel grading was found to be statistically significant ( $\mathrm{P}=0.0005)$. Patients with combined approach showed higher percentage of neurologic improvement (62\%) while patients with posterior approach showed only $35 \%$ improvement in their neurologic status. This was statistically insignificant $(\mathrm{P}=0.2835)$. Also, there was no significant relation found between improvement of Frankel grading and the number of involved columns $(\mathrm{P}=0.4013)$. Pain improved in all patients except 6 (25\%) who still had pain after decompression. Correlation between approach and pain at the final follow-up was statistically significant $(\mathrm{P}=0.0001)$. Also, statistically significant relationship was found between the number of involved columns and pain $(\mathrm{P}=0.0117)$. The surgical approach used was based on the location and the extent of the lesion. Because the anterior spinal elements were involved in most patients, a combined approach was used in 18 (69.3\%). Statistical correlation between the level of involvement and the approach was insignificant $(\mathrm{P}=0.4366)$. In $21(80.8 \%)$ patients different type's internal fixation was used, most of them were posteriorly placed. In the thoracolumbar region, eight patients needed more than 6-segment stabilization $(30.77 \%)$, while in the lumbar region 10 patients needed 2-3 segments stabilization (38.46\%).

The pre-operative kyphotic angle was 37.7 degrees (range, 15-60 degrees) for the thoracolumbar cases and -8 degrees (range, -35 to 35 degrees) for the lumbar cases. At the final follow-up, the Kyphotic angle was 18.14 degrees (range, 7-45 degrees) for the thoracolumbar cases and -8.9 degrees (range, -30 to 30 degrees) for the lumbar cases. No statistical significance was found between the number of columns and the Kyphotic angle whether pre-operatively $(\mathrm{P}=0.669)$ or postoperatively $(\mathrm{P}=0.685)$.

\section{Complications}

Two patients had reoperation. One patient due to loosening of the implant (there were no complaints from the patient side. Only in the $\mathrm{x}$-ray during follow up) and the other due to wound necrosis and gapping.

\section{Discussion}

Involvement of the spine by metastatic disease is common. If these metastases left untreated, patients will become totally paraplegic, experience severe pain and require intensive nursing care. Radiotherapy had less than $50 \%$ effectiveness in maintaining the patient ability to walk [11]. McBroom et al. [12] reviewed retrospectively 164 patients who were treated with therapeutic irradiation. $78 \%$ of ambulatory patients at presentation remained so and only $28 \%$ of the non-ambulatory patients regained sphincter control. Failure to respond to radiotherapy increased significantly with kyphosis $>15 \%$, vertebral collapse $>50 \%$ or with vertebral displacement $5 \%$. They concluded that radiotherapy alone is likely to fail. Therefore, once the metastatic destruction of the vertebra progresses and spinal collapse occurs, radiation therapy may no longer be effective, and surgical treatment may be indicated [13-16]. In terms of average neurological recovery after spinal decompression, the end results of this study are encouraging apart from those patients with complete paraplegia (3 patients) (Table 3 ).

The spinal instability is mechanically related to extensive bone destruction and leads to severe pain and neurological deficit. Neither radiation therapy nor chemotherapy, even if successful in controlling the tumor, will alleviate the pain taking into consideration the type of the tumor and the degree of differentiation [17]. These measures will of course affect the cord. As in the treatment of pathological fractures of long bones, stabilization of the vertebral segments is required for pain relief. Patients with posterior approach showed 35\% neurological improvement and this was similar to that found by Byrne [18] but much lower than that reported by Bauer [19] and Rompe [5]. Patients with combined approach showed $62 \%$ neurologic improvement similar to that reported in the literature [20-22].

Surgical approaches have ranged from limited posterolateral decompression to more aggressive anterior approaches and vertebral body resection [1]. Although a single approach may suffice in most patients; radiographic studies frequently demonstrate three-column involvement or marked instability of the spine. In such patients, a purely posterior or anterior approach does not provide sufficient access for tumor resection or correction of the instability. However, results obtained from direct anterior approaches using vertebrectomy and anterior reconstruction of the anterior and middle columns have produced the best results in terms of neurological improvement [20]. In a meta-analysis of the literature, Kostuik and Weinstein [23] noted that $80 \%$ of his patients treated by the anterior approach had a satisfactory outcome, whereas only $37 \%$ treated by posterior approaches had similar results.

The concept of anterior-posterior surgery with instrumentation is based on experimental biomechanical considerations, as well as on the goal of accomplishing total tumor resection. The anterior-posterior construct was able to restore axial, sagittal, and torsional stiffness of the spine in metatstatic disease [24]. Harms [25] has suggested that anterior-posterior reconstruction should be used in all cases of tumors. Because $70 \%$ to $90 \%$ of the axial load passes through the vertebral body, the anterior construct should be strong enough to resist axial loads and torsion stresses. Posteriorly, tensile stresses predominate and should be counteracted using a short segment compression construct. Cooper and associates [2] have suggested that the technique of reconstruction should be based on the location of the tumor as well as the number of columns involved. For three-column involvement between T-2 and $\mathrm{T}-10$, they suggested vertebral body reconstruction and posterior instrumentation; between T-11 and L-4, they recommended anterior body reconstruction with both anterior and posterior instrumentation 
since anterior implants provide limited torsion stiffness. Since most cases involve both the vertebral bodies and pedicles (signifying threecolumn involvement), this would imply that all patients would require combined anterior-posterior stabilization. Kostuik and Weinstein [23] therefore divided the three-column spine into six segments by subdividing each column into right and left halves; the spinal column was considered unstable if three to four segments were destroyed.

In this study, almost all patients had 2 or 3 columns involvement but the results did not support the three columns theory. We could not correlate any significant results between pre- and post-operative radiographic measurements (mechanical instability) or pre- and postoperative neurologic findings (neurologic instability) and the number of involved columns. This may be explained by all the metastatic tumors involve the anterior and the middle columns and in our series the 3 columns were reconstructed after tumor removal.

Irrespective of the type of decompression, stabilization of the spine is important to protect the neural elements from undue instability and minimize painful spinal motion. Pedicular fixation was used in $18 / 24$ (75\%) patients. A pedicle fixator obviously acts as a load-bearing rather than a load-sharing device, therefore one would expect such a construct to be of limited longevity $[26,27]$. Surprisingly no patient in our series, including those surviving 18 months or longer, reported any symptoms indicative of implant problems because of the anterior construct of bone cement or grafting technique used for the anterior column that had a shear-bearing effect $[28,29]$. Similarly, the degree of involvement of the spinal column is expected to be more important determinant of the outcome than the surgical procedure [1].

The major impact of any treatment on cancer patient is measured both in the duration and quality of survival. In this regard, most patients were late after exhausting the other available therapeutic options. They also followed-up their problem with oncologists and radiation therapists.

\section{Conclusion}

Results obtained from direct anterior approaches using corpectomy and anterior reconstruction of the anterior and middle columns have produced the best results in terms of neurological improvement. Therefore, direct anterior approach and posterior spinal instrumentation should be done for all metastatic spinal tumors.

\section{References}

1. Sundaresan N, Steinberger AA, Moore F, Sachdev VP, Krol G, et al. (1996) Indications and results of combined anterior-posterior approaches for spine tumor surgery. J Neurosurg 85: 438-446.

2. Cooper PR, Errico TJ, Martin R, Crawford B, DiBartolo T (1993) A systematic approach to spinal reconstruction after anterior decompression for neoplastic disease of the thoracic and lumbar spine. Neurosurgery 32: 1-8.

3. Fessler RG, Dietze DD Jr, Millan MM, Peace D (1991) Lateral parascapular extrapleural approach to the upper thoracic spine. J Neurosurg 75: 349-355.

4. Harrington KD (1988) Anterior decompression and stabilization of the spine as a treatment for vertebral collapse and spinal cord compression from metastatic malignancy. Clin Orthop Relat Res : 177-197.

5. ROMPE JD, Eysel P, Hopf C (1993) Decompression/stabilization of the metastatic spine. Cotrel-Dubousset instrumentation in 50 patients. Acta Orthop Scand 64:3-8.

6. Siegal T, Tiqva P, Siegal T (1985) Vertebral body resection for epidura compression by malignant tumors. Results of forty-seven consecutive operative procedures. J Bone Joint Surg Am 67: 375-382.

7. Livingston KE, Perrin RG (1978) The neurosurgical management of spinal metastases causing cord and cauda equina compression. J Neurosurg 49: 839-843.
8. Denis F (1988) thoracolumbar spine injuries: Classification. Current Orthopedics 2: $214-217$.

9. Siegal T (1995) surgical management of malignant epidural tumors compressing the spinal cord, in schmidek HH, Sweet WH (eds.): Operative Neurosurgical Techniques. Indications, Methods, and results, Ed 3, Philadelphia: WB Saunders: 1997-2025.

10. Bradford DS, McBride GG (1987) Surgical management of thoracolumbar spine fractures with incomplete neurologic deficits. Clin Orthop Relat Res : 201-216.

11. Kocialkowski A, Webb JK (1992) Metastatic spinal tumours: survival after surgery. Eur Spine J 1: 43-48.

12. McBroom RJ, Dooley JF, Blend R. Failure of radiotherapy for metastatic spinal disease can be predicted. Trans-actions of the 57 th annual meeting of the American Academy of Orthopedic Surgeons, 1990; February 8-13.

13. Harrington KD (1986) Metastatic disease of the spine. J Bone Joint Surg Am 68: $1110-1115$

14. Siegal T, Siegal T (1985) Surgical decompression of anterior and posterior malignant epidural tumors compressing the spinal cord: a prospective study. Neurosurgery 17: 424-432.

15. Siegal T, Siegal T (1985) Vertebral body resection for epidural compression by malignant tumors. Results of forty-seven consecutive operative procedures. $J$ Bone Joint Surg 67: 375-382

16. Tomita T, Galicich JH, Sundaresan N (1983) Radiation therapy for spinal epidural metastases with complete block. Acta Radiol Oncol 22: 135-143.

17. Galasko CS, Norris HE, Crank S (2000) Spinal instability secondary to metastatic cancer. J Bone Joint Surg Am 82: 570-594.

18. Byrne TN (1992) Spinal cord compression from epidural metastases. N Engl J Med 327: 614-619.

19. Bauer HC (1997) Posterior decompression and stabilization for spinal metastases. Analysis of sixty-seven consecutive patients. J Bone Joint Surg Am 79: 514-522.

20. Sundaresan N, Galicich JH, Lane JM, Bains MS, McCormack P (1985) Treatment of neoplastic epidural cord compression by vertebral body resection and stabilization. J Neurosurg 63: 676-684.

21. Hosono N, Yonenobu K, Fuji T, Ebara S, Yamashita K, et al. (1995) Orthopaedic management of spinal metastases. Clin Orthop Relat Res : 148-159.

22. Sucher E, Margulies JY, Floman Y, Robin GC (1994) Prognostic factors in anterior decompression for metastatic cord compression. An analysis of results. Eur Spine J 3: 70-75.

23. Kostuik KP, Weinstein JN (1991) Differential diagnosis and surgical treatment of metastatic spinal tumors, in Frymoyer JW (Ed): The Adult Spine: Principles and Practice. New York: Raven Press: 861-888.

24. Heller JG, Zdeblick TA, Kunz DA, McCabe R, Cooke ME (1993) Spina instrumentation for metastatic disease: in vitro biomechanical analysis. J Spinal Disord 6: 17-22.

25. Harms J (1992) Screw-threaded rod system in spinal fusion surgery. Spine: State of Art Reviews 6:541-575.

26. Olerud S, Karlström G, Sjöström L (1988) Transpedicular fixation of thoracolumbar vertebral fractures. Clin Orthop Relat Res 227: 44-51.

27. Jónsson B, Sjöström L, Olerud C, Andréasson I, Bring J, et al. (1996) Outcome after limited posterior surgery for thoracic and lumbar spine metastases. Eur Spine J 5: 36-44.

28. Krikler SJ, Marks DS, Thompson AG, Merriam WF, Spooner D (1994) Surgical management of vertebral neoplasia: who, when, how and why? Eur Spine $J$ 3: $342-346$.

29. Sapkas G, Kyratzoulis J, Papaioannou N, Babis G, Rologis D, et al. (1997) Spinal cord decompression and stabilization in malignant lesions of the spine. Acta Orthop Scand Suppl 275: 97-100. 